\title{
Integrating urban ecosystem sustainability assessment into policy-making: insights from the Gold Coast City
}

\section{Didem Dizdaroglu \& Tan Yigitcanlar}

To cite this article: Didem Dizdaroglu \& Tan Yigitcanlar (2016) Integrating urban ecosystem sustainability assessment into policy-making: insights from the Gold Coast City, Journal of Environmental Planning and Management, 59:11, 1982-2006, DOI: 10.1080/09640568.2015.1103211

To link to this article: https://doi.org/10.1080/09640568.2015.1103211

曲 Published online: 10 Mar 2016.

Submit your article to this journal $₫$

Џ Article views: 320

Q View related articles $\sqsubset$

View Crossmark data ð

4 Citing articles: 12 View citing articles 


\title{
Integrating urban ecosystem sustainability assessment into policy-making: insights from the Gold Coast City
}

\author{
Didem Dizdaroglu ${ }^{\mathrm{a} *}$ and Tan Yigitcanlar (1) ${ }^{\mathrm{b}}$ \\ ${ }^{a}$ School of Urban Design and Landscape Architecture, Urban Design and Landscape Architecture \\ Department, Bilkent University, Ankara, Turkey; ${ }^{b}$ School of Civil Engineering and Built \\ Environment, Civil Engineering and Built Environment Department, Queensland University \\ of Technology, Brisbane, Australia
}

(Received 7 September 2014; final version received 30 September 2015)

\begin{abstract}
This paper introduces a policy-making support tool called 'Micro-level Urbanecosystem Sustainability IndeX (MUSIX)'. The index serves as a sustainability assessment model that monitors six aspects of urban ecosystems - hydrology, ecology, pollution, location, design, and efficiency - based on parcel-scale indicators. This index is applied in a case study investigation in the Gold Coast City, Queensland, Australia. The outcomes reveal that there are major environmental problems caused by increased impervious surfaces from growing urban development in the study area. The findings suggest that increased impervious surfaces are linked to increased surface runoff, car dependency, transport-related pollution, poor public transport accessibility, and unsustainable built environment. This paper presents how the MUSIX outputs can be used to guide policy-making through the evaluation of existing policies.
\end{abstract}

Keywords: urban ecosystem; sustainability assessment; composite index; parcel-scale spatial analysis; Gold Coast City

\author{
Abbreviations \\ DPSIR: Driving force-Pressure-State-Impact-Response \\ FEEM: Fondazione Eni Enrico Mattei \\ GCCC: Gold Coast City Council \\ MUSIX: Micro-level Urban-ecosystem Sustainability Index \\ UNEP: United Nations Environment Programme \\ BREEAM: Building Research Establishment Environmental Assessment Methodology \\ LEED: Leadership in Energy and Environmental Design \\ CASBEE: Comprehensive Assessment System for Building Environmental Efficiency
}

\section{Introduction}

An urban ecosystem is characterized as a combination of artificial and natural ecological systems, where people built their settlements on the remnants of natural ecosystems and form a complex structure that mimics their functions (Guidotti 2010). Sustainable design of the urban ecosystem is based on reshaping the patterns of cities - including urban form, architecture, design of infrastructure and other support systems, social and economic processes - to mimic the processes of natural ecosystems, so that the resulting

*Corresponding author. Email: dizdaroglu@bilkent.edu.tr 
effects will be relatively natural. A sustainable urban ecosystem is defined by Newman and Jennings $(2008,108)$ as "ecosystems which are ethical, effective (healthy and equitable), zero-waste, self-regulating, resilient, self-renewing, flexible, psychologically-fulfilling and cooperative". To assess environmental performance, examine ecological limits and provide the long-term protection of environmental quality within an urban ecosystem, sustainability assessment is needed to be integrated into planning process. It aids planners and policy makers in formulating sustainable policies through monitoring environmental problems and their impacts on the natural environment (Yigitcanlar 2010). As outlined by the UNEP (2004), sustainability assessment provides the following benefits:

- Supporting sustainable development: The assessment results (1) highlight the economic, social, environmental opportunities and constraints; (2) organize the policy- and decision-making process by reducing the complexity of each stage, and; (3) help governments to reach proposed sustainability targets;

- Facilitating good governance and institution-building: The integrated assessment (1) promotes the transparency of the policy- and decision-making process; (2) helps build social consensus about its acceptability, and; (3) enhances coordination and collaboration between different government ministries and bodies;

- Saving time and money: The integrated assessment (1) strengthens the intersectoral policy coherence; (2) provides early warning of the potential problems, and; (3) minimizes environmental, social and health impacts, thereby reducing the costs required to remedy them;

- Enhancing participatory planning for sustainable communities: The integrated assessment (1) increases the awareness of governments and citizens on the significance of ecosystem functioning, and; (2) strengthens national commitment to sustainable development.

Although many approaches exist (Hardi et al. 1997; Ness et al. 2007; Singh et al. 2009; Srinivasan et al. 2011), the research on employing different assessment tools and methodologies to help policy- and decision-making is still in progress. An example of the methodology for urban ecosystem sustainability assessment, which measures the interaction between human and ecosystem well-being, developed by the International Union for Conservation of Nature and Natural Resources consists of seven stages as follows (Guijt and Moiseev 2001):

- Determine the purpose of the sustainability assessment: In this step, the purpose and objectives of the assessment are clarified;

- Define the system and goals: The geographic area for the assessment is defined. A vision and goals for sustainable development are developed and recorded;

- Clarify dimensions, identify elements, and objectives: The dimensions, which will be used for measuring performance towards sustainable development are developed. Data collection and storage are carried out;

- Choose indicators and performance criteria: All selected indicators are explained in detail and the performance criteria for each indicator are justified;

- Gather data and map indicators: The indicator scores are calculated and the scores are mapped;

- Combine indicators and map the indices: The indicator scores are aggregated into an index through some methodological steps and the scores are mapped in order to explain the findings easily; 
- Review results and assess implications: This step involves the analysis of the results, causes, implications, and identification of the priorities for improvement. The results give a snapshot of the current situation and the findings help to determine the policies and actions.

The main objectives of this research are: (1) identify the environmental impacts of development on the urban ecosystem and its components; (2) develop a set of indicators to define the environmental pressures at micro-level spatial unit, and; (3) establish a parcel-scale composite index to evaluate the efficiency of implemented policies. In light of these objectives, the paper introduces a new sustainability assessment tool called 'Micro-level Urban-ecosystem Sustainability IndeX (MUSIX)'. In recent years, an increasing number of sustainability indicators/indices have been developed to evaluate environmental impacts at the macro-level from national to regional and international scales. However, these studies report multiple barriers in terms of micro-level spatial data availability in the indicator development process, which raised the issue of missing data treatments (Dizdaroglu 2015). As stated by Alberti $(2008,102)$, the smallest spatial unit produces information that varies from household/building to street/parcel-scales. These parcels then combine to create new functional units as suburbs/neighbourhoods which interact with regional/national-scales. In this context, MUSIX provides a methodological approach for identifying a set of parcel-scale indicators that can be used for monitoring the impacts of development on urban ecosystem components. In the case of Gold Coast City, MUSIX detects the sustainability performance of a residential area referring to six main issues of urban development - i.e., hydrology; ecology; pollution; location; design, and; efficiency. For each category, a set of core indicators is assigned in order to evaluate the progress towards sustainable development. While the indicators of the model provide specific information about the environmental problems in the area (e.g., irregular-shaped lots covered by large impervious surfaces, increased surface runoff, limited access to local services/amenities within walking distance, inadequate public transport services, lack of climate responsive landscape design), the composite index score produces a big picture view of the sustainability performance of the neighbourhood (e.g., loss of natural vegetation, stormwater management issues, auto-dependent pattern of development, transport-related pollution, consumption of non-renewable resources). In the light of the model findings, existing policies are evaluated to guide the preparation and assessment of development and local area plans in conjunction with the Gold Coast Planning Scheme, which establishes regulatory provisions to achieve sustainable development.

The paper is structured as follows. Following this introduction, Section 2 introduces salient characteristics of the case study area, planning policies of the local council, structure of the MUSIX. In light of the model findings, Section 3 presents the interpretation of the model results and evaluation of existing policies. Section 4 concludes the paper with useful insights from the application of the model.

\section{Materials and methods}

\subsection{Case study area: the Gold Coast City}

This study is part of a joint Australian Research Council project that aims to develop recommendations for the adaptation of current water sensitive urban design (WSUD) practices to climate change, changing urban form, and future transport systems. The Gold 

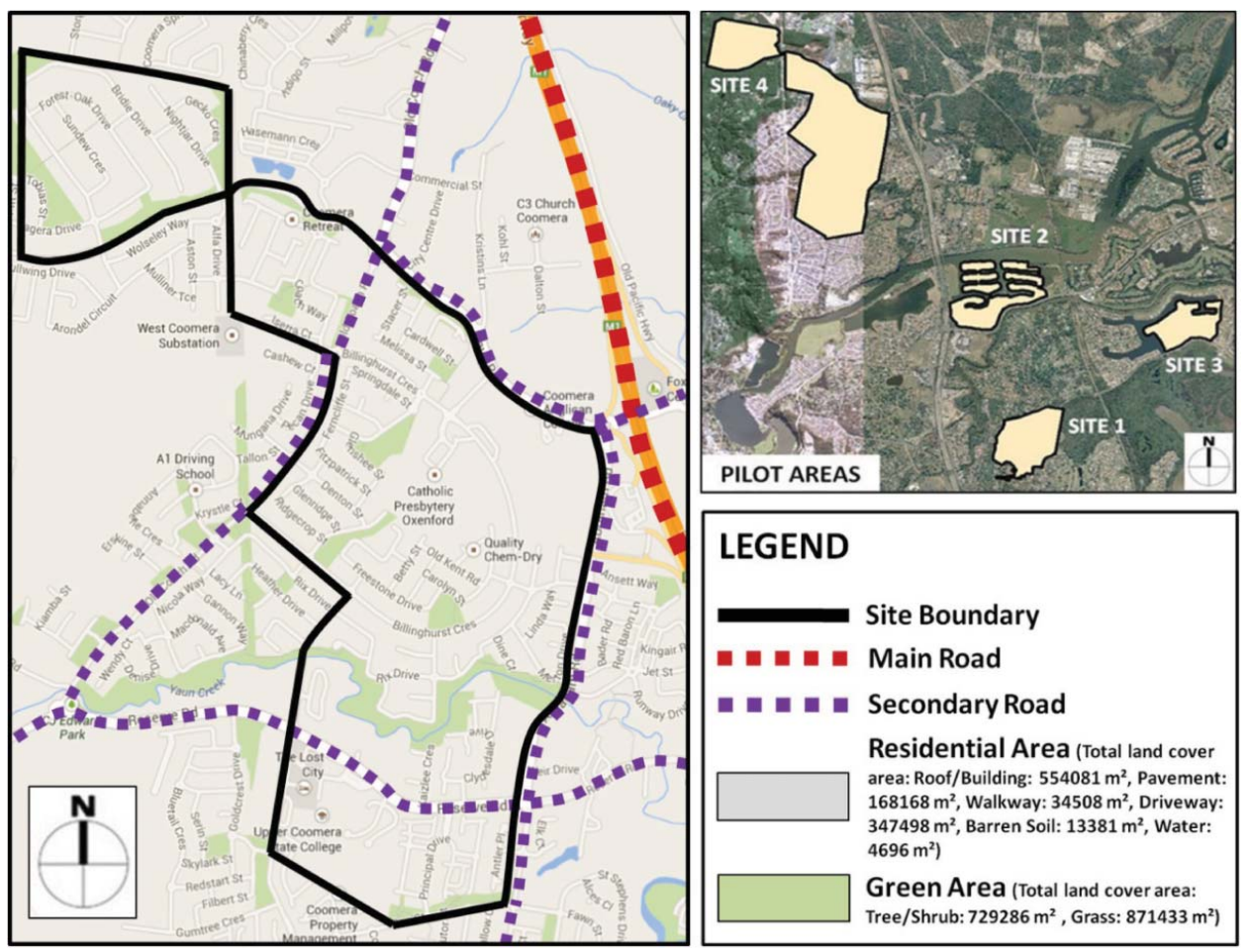

LEGEND

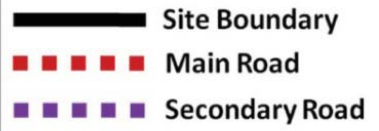

Residential Area (Total land cover area: Roof/Building: $554081 \mathrm{~m}^{2}$, Pavement: $168168 \mathrm{~m}^{2}$, Walkway: $34508 \mathrm{~m}^{2}$, Driveway: $347498 \mathrm{~m}^{2}$, Barren Soil: $13381 \mathrm{~m}^{2}$, Water: $4696 \mathrm{~m}^{2}$ )

Green Area (Total land cover area: Tree/Shrub: $729286 \mathrm{~m}^{2}$, Grass: $871433 \mathrm{~m}^{2}$ )

Figure 1. Location of the pilot-test area in the Gold Coast City.

Coast City is chosen as the test bed for this project. The Gold Coast City is located on the Eastern coast of Australia in the South East of the State of Queensland. The city is a tourist attraction and vibrant economic hub covering an area of $1,334 \mathrm{~km}^{2}$. The city shows a linear development, which includes a high rise coastal strip surrounded with highways, canal estates, and low-density housing developments mixed with entertainment, employment, and retail activities (GCCC 2008). The population of the city is approximately 546,067 and the population density is 4.09 persons per hectare. In order to ensure data and content integrity within the project, four pilot sites, as shown in Figure 1, are selected for the implementation of MUSIX. In this paper, the findings of Site 4 are presented. Site 4 is a high-density residential area located in Upper Coomera, which is one of the rapidly growing suburbs located at the Northern end of the city, with a population of 21,136, including mostly low-income groups (ABS 2015). Wetlands and sugar cane lands are located on the eastern boundary. On the west, the suburb is bounded by Brygon Creek which flows into the Coomera River and Hotham Creek. The suburb has an undulated topography that forms a steep valley to the West. This steeper land is a vegetated land that is threatened by potential future residential development. The suburb includes a popular theme park, Dreamworld, a major shopping centre, and a university campus, as well as being close to the Gold Coast railway line and the Pacific Motorway (GCCC 2012). A general map of the area is shown in Figure 1 (Google Maps 2013). The area consists of detached single and two-storey lot dwellings with backyard gardens. The total size of the pilot area is approximately 272 hectares and the total number of parcels is 1,515 . 


\subsection{Overview of the existing planning policies}

The Gold Coast City confronts major environmental problems depending on population growth, rapid urbanization, and expanding transport infrastructure. These environmental pressures have significant impacts on coastal environments and water resources. According to the 'Our Living City Report' published by GCCC (2006), some of these pressures include (1) local air pollution emissions from growing economic activity and vehicle use; (2) clearing and habitat destruction; (3) beach erosion due to foreshore development and unnecessary use for recreational purposes; (4) land degradation, particularly canal constructions; (5) increased urban development as well as a growing number of tourists, visitors, and day-trippers, and; (6) increased demand for clean and safe drinking water. The City Council responds to these challenges by developing strategies, plans, and programs that help to protect its ecosystems and support sustainable management of its resources under the Sustainable Planning Act 2009. This Act was introduced by the Queensland Government to assist state and local governments with achieving ecological sustainability in planning. Additionally, the Corporate Plan 2020 sets out key strategies towards city's vision under three themes, (1) the best place to live and visit; (2) prosperity built on a strong diverse economy, and; (3) people contribute to a strong community spirit (GCCC 2015a). This plan is supported by other key documents, such as the Gold Coast Planning Scheme 2003. The planning scheme establishes regulatory provisions to achieve ecological sustainability through the formulation of place codes, development codes, constraint codes, and other assessment criteria that provide guidance for best practice development solutions (GCCC 2008). The Draft City Plan 2015, which is city's new planning scheme in the final stages of the approval process, will replace the Gold Coast Planning Scheme 2003. Key aims include facilitating new housing, providing catalysts for jobs, key infrastructure connections, and protecting the environment from urban sprawl. In addition, this plan will help the city take full advantage of the significant opportunities ahead, including the Gold Coast 2018 Commonwealth Games, revitalization of key centres, such as the CBD (Central Business District) in Southport, and investment in transport infrastructure, such as light rail (GCCC 2015b).

\subsection{The MUSIX model}

The MUSIX model is constructed by the following steps.

\subsubsection{Theoretical framework}

The theoretical framework of the MUSIX is based on developing a sustainable urban ecosystem which aims to integrate human activities into natural systems by carrying out environmental policies to ensure their long-term sustainability. To achieve a sustainable urban ecosystem, MUSIX focuses on two overarching objectives which constitute the main categories of the indicator set, (1) ecological resilience of natural environment by preserving the ecosystem's stability through improving its resistance to tolerate the damage of human activities, and; (2) sustainable design of built environment towards eco-friendly architectural design and urban planning. In light of these objectives, MUSIX incorporates six main goals that aim to achieve a sustainable urban ecosystem, (1) hydrological conservation; (2) ecological protection; (3) environmental quality; (4) sustainable urban design; (5) the use of renewable resources, and; (6) sustainable mobility and accessibility. These sub-categories consist of 14 indicators, presented in Table 1. 


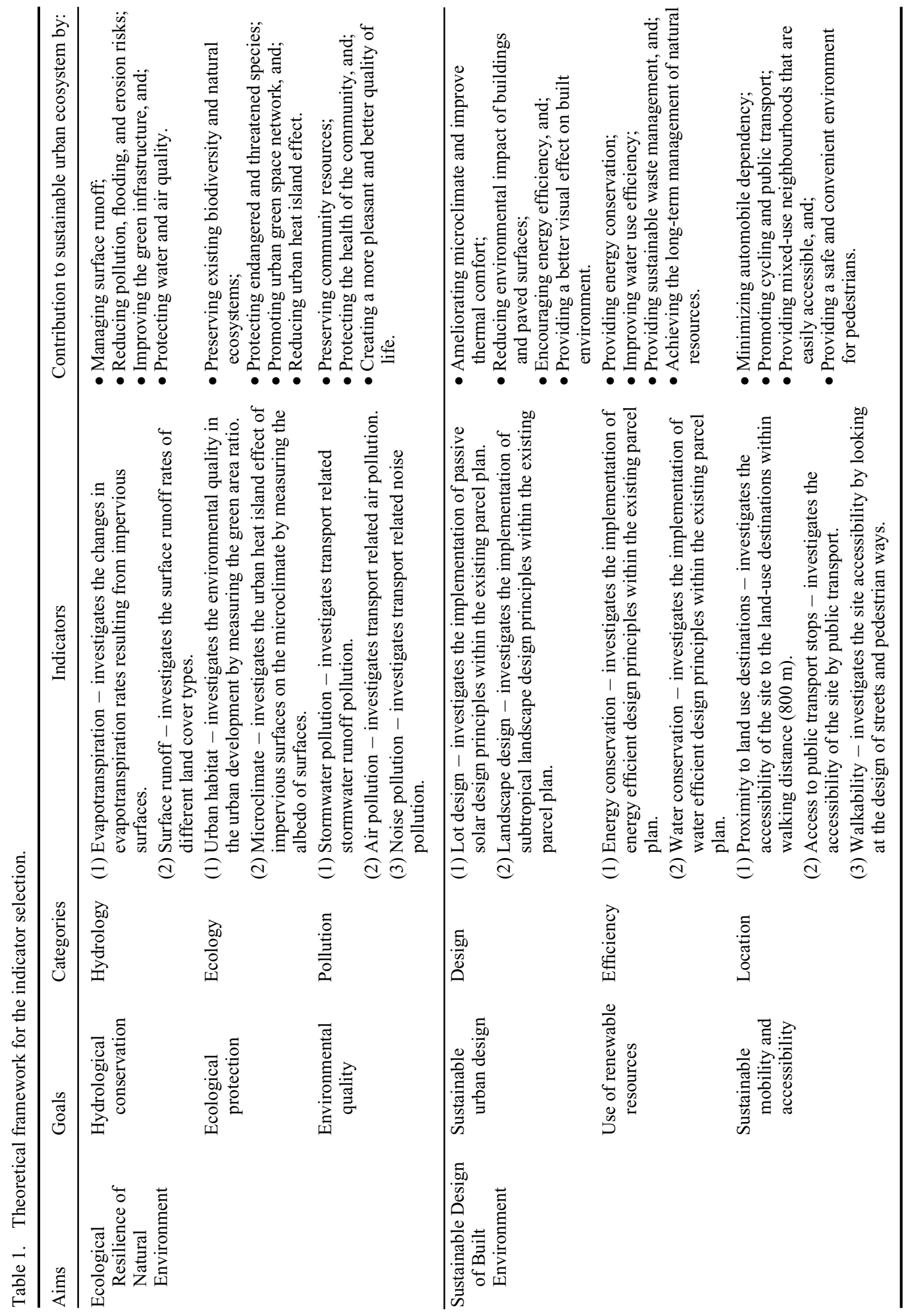




\subsubsection{Indicator selection and data collection}

The indicator set presented in Table 1 was developed through a comprehensive review of existing indicator initiatives (UNCSD 2001; OECD 2003; EEA 2005; Japan Sustainable Building Consortium 2007; SEDAC 2007; US Green Building Council 2008, 2009). Additionally, an expert panel was established to reach a consensus on the desired indicators. The panel members were composed of academics, researchers, and professionals who are familiar with the characteristics of the local area and existing planning policies. Through a series of workshops, experts provided useful insights into the selection of relevant indicators for the policy formulation process. MUSIX utilized the best environmental data available and indicators were selected through consideration of the local environmental problems within the pilot test-bed Gold Coast City.

\subsubsection{Normalization and calculation of indicators}

Benchmarking normalization was employed to remove the scale effects of different units by standardizing the original indicator units to normalized units. Indicator scores are ranked by applying benchmarks according to the normalized values that are given regarding whether the indicator value is above/below/around that threshold value. These threshold values for each indicator were assigned by reviewing various studies in the literature (see Appendix 1 detailing calculation method and benchmark values used to evaluate performance of each indicator). Similar to the five-point Likert scale used for the FEEM sustainability index (Carraro et al. 2009), each indicator is expressed as a value between 1 and 5 indicating different levels of sustainable targets, (1) low (extremely unsustainable situation); (2) medium-low (not sustainable but not as severely as in the previous level); (3) medium (a discrete level of sustainability); (4) medium-high (satisfactory level of sustainability but not on target), and; (5) high (target level of sustainability).

\subsubsection{Multivariate analysis}

A statistical analysis was employed to examine the underlying structure of the data. First, a Kolmogorov-Smirnov test was performed to investigate the distribution of the indicator data-set. As a result of the non-normal distribution of the data-set, the Spearman's rank correlation analysis was conducted to examine the relationship between the indicators with reference to similar studies (e.g., Pinho and Manso Orgaz 2000; Raju, Lucien, and Arondel 2000; Saltelli et al. 2004; Dramstad et al. 2006; Schulman and Peters 2008; Can et al. 2011; Rinner and Hussain 2011). The correlation between the indicator data-sets is presented in Appendix 2. A high correlation was found between 'evapotranspiration (ISR)' and 'surface runoff (SR)' $(r=0.734)$, 'stormwater pollution (SW)' and 'air pollution (AIR)' ( $r=0.648)$, and 'proximity to land-use destinations (LUD)' and 'access to public transport (PT) stops' ( $r=0.731)$ indicators. A correlation coefficient ratio 0.8 was taken as the benchmark value as suggested (Katz 1999; Lehman et al. 2005; Morien 2006; Christmann and Badgett 2009). It needs to be mentioned that this analysis was conducted with normalized indicator values (between 1 and 5) which narrowed the range of data and resulted in a decrease in standard deviations and an increase in the correlation coefficients. Hence, it was expected to see a high correlation between the scores. Additionally, these indicators measure different variables by using 
different calculation methods. Based on the literature, these correlations can be interpreted as follows:

- large amounts of impervious surfaces (ISR) are associated with increased SR;

- stormwater pollution (SW) is associated with air pollution (AIR), which means transport-related pollutants become washed off during a rainfall from paved surfaces by causing stormwater pollution;

- proximity to LUD is related with access to PT, which means sustainable mobility encourages PT by providing easier access and shorter times to get to the destination.

\subsubsection{Spatial analysis}

Spatial analysis of the study area was carried out through aerial remote sensing data with the use of ArcGIS software. From visual and digital interpretations of the aerial photo imagery derived from Google Maps, the total area of each land cover type within parcels was measured by using the ArcGIS Analysis tool. The land cover classification was based on nine main types: roof-building; pavement; driveway; cycleway; walkway; tree-shrub; water; turf-grass; and barren soil.

\subsubsection{Weighting}

For this study, expert opinion weighting was selected due to the spatial scale and scope of the research. MUSIX is developed to measure the local-level environmental performance of an urban area. In this sense, consultation of local experts' opinion helps to reflect the implications of the existing planning policies, local environmental issues and needs of the study area. Second, MUSIX is developed as an assessment tool to serve in the policymaking process. In this sense, the model results are highly benefited from the input from developers, planners, and policy makers that consist of the expert survey participants. The results indicate that experts assigned 'energy conservation' as the most important indicator. The reason for this is the study area is located in a sub-tropical zone which faces high temperature and humidity all year round. In this climate, energy efficiency is critically important to avoid high energy use of air conditioning systems and reduce greenhouse gas emissions. Passive solar design is an advantage in hot and humid climates to minimize energy use. The results indicate that experts assigned 'noise pollution' as the least important indicator. The reason for this is that there is no commercial, transport, or construction noise problems at a level that adversely impacts on the quality of life of residents in the area. However, neighbourhood noise from residential premises, animals, air conditioners, loud music, or alarms might be an issue which cannot be detected during expert surveys. The results also showed that all indicators met the minimum required relevance rate of 3 and above, so that they were confirmed by experts as key components in sustainability assessment.

\subsubsection{Aggregation}

This step is composed of two different aggregation stages. First, an arithmetic aggregation was conducted. Additive aggregation is basically the arithmetic average of the weighted and normalized indicator scores. The composite index score was calculated by the 
following equation:

$$
\text { MUSIXCI }=\sum_{i=1}^{n} w_{i} \cdot x_{i}
$$

where $\mathrm{CI}$ is the composite indicator value, $n$ is the number of indicators, $w_{i}$ is the weight for indicator $i$, and $x_{i}$ is the normalized indicator value.

Second, a spatial aggregation was conducted. The study area was divided into 100 metre $\times 100$ metre grid cells and ArcGIS software was used to transfer parcel-scale aggregated composite index scores into grid cell scores. The aggregation of geographical data is widely used in the analysis of urban systems (Dur, Yigitcanlar, and Bunker 2014). However, there are many challenges, such as the modifiable areal unit problem, which is a widely recognized spatial analytical issue that affects the results of such analyses due to the scale or zoning of the space (Paez and Scott 2004). If the areal units are too small the results might not be meaningful, in contrast, if they are too big the results might not be accurate. Therefore, an interim scale is necessary in order to avoid detection issues. In order to investigate the sensitivity of the changes that occurred from different spatial scales, descriptive statistics of aggregated data were performed for 50, 100, and 150 metre grid cell sizes. Eventually, the 100-metre grid cell was selected as the spatial unit based on the acceptable results from the analysis (Dizdaroglu and Yigitcanlar 2014). Each parcel's composite index score is multiplied by its area percentage within the grid cell and then summed into a single composite score for each grid cell. Finally, the composite index score was presented in five comparative sustainability levels: as suggested by Yigitcanlar et al. (2007), low (0.00-1.00), medium-low (1.01-2.00), medium (2.01-3.00), medium-high (3.01-4.00), and high (4.01-5.00).

\subsubsection{Sensitivity analysis}

Each composite index is constructed by several subjective steps, which include the calculation method, selection of indicators, choice of aggregation, and weighting procedures that are associated with some uncertainties in the methodology. Therefore, it is necessary to analyse the sensitivity of the index by using alternative methodological assumptions. In this context, as the first part of the sensitivity analysis, alternative techniques were applied in the weighting and aggregation procedures, as follows: (1) equal weighting which provides the measurement of each indicator with the same degree of importance; (2) factor analysis which allows investigating a statistical relationship to determine the importance of each indicator, and; (3) geometric aggregation which allows investigating the correlation among the performance of the indicators. The composite index scores were calculated by using different combinations of alternative methodological techniques, as illustrated in Appendix 3. The calculation based on 'Expert Opinion Weighting and Geometric Aggregation', 'FA Weighting and Geometric Aggregation', and 'Expert Opinion Weighting and Geometric Aggregation' yield lower sustainability results compared to the MUSIX model results. Specifically, FA weighting with geometric aggregation performed negative differences in a couple of grid cells compared to other scenarios. The underlying reason for this difference depends on the fact that geometric aggregation uses multiplication to summarize data; hence, it performs lower scores than arithmetic aggregation. In order to assess the overall impact of these different methodological assumptions on the MUSIX model results, Spearman's rank correlation analysis was performed with reference to a number of similar studies (Groh, 
Table 2. Correlation between the MUSIX model results and different methodological assumptions.

Correlation with the implemented method (expert opinion weighting,

Alternative calculation methods linear aggregation)

Equal weighting, linear aggregation

$0.995^{* *}$

FA weighting, linear aggregation

$0.988^{* *}$

Equal weighting, geometric aggregation

$0.985^{* *}$

FA weighting, geometric aggregation

$0.975^{* *}$

Expert opinion weighting, geometric aggregation

$0.990^{* *}$

${ }^{* *}$ Correlation is significant at the 0.05 level (two-tailed).

von Liechtenstein, and Lieser 2008; Groh and Wich 2009; Saisana 2010). Due to the large data-set, the level of significance was set at 0.05 and a two-tailed test was chosen to identify the level of significant differences between the indicator data-set in either direction. The results revealed that the impact of any of these assumptions is negligible overall, as the correlations between the MUSIX model results and the others are greater than 0.9 (Table 2).

As the second part of the sensitivity analysis, the impact of an underlying indicator on overall outcome of the model was assessed through performing exclusion of one indicator at a time. The analysis was conducted via removing one indicator at a time and then recalculating a reduced model score (Table 3). A low correlation between the MUSIX score and reduced model score implies that the model is highly sensitive to the exclusion of that indicator. The analysis revealed that the correlation between the MUSIX score and the reduced model scores are greater than 0.5 , which reveals that the model is robust to small changes in the indicator set.

Table 3. Correlation between the MUSIX model score and reduced model scores.

Reduced model

Evapotranspiration removed

Surface runoff removed

Urban habitat removed

Microclimate removed

Stormwater pollution removed

Air pollution removed

Noise pollution removed

Proximity to land-use destinations removed

Access to public transport stops removed

Walkability removed

Lot design removed

Landscape design removed

Energy conservation removed

Water conservation removed

The MUSIX model
Spearman's correlation
$0.727^{* *}$
$0.657^{* *}$
$0.607^{* *}$
$0.630^{* *}$
$0.674^{* *}$
$0.808^{* *}$
$0.563^{* *}$
$0.696^{* *}$
$0.709^{* *}$
$0.861^{* *}$
$0.699^{* *}$
$0.759^{* *}$
$0.661^{* *}$
$0.641^{\text {** }}$
1.000

\footnotetext{
${ }^{* *}$ Correlation is significant at the 0.05 level (two-tailed).
} 


\section{Interpretation of the model results and evaluation of existing policies}

Findings of the MUSIX are presented in a clear and accurate manner through ArcGIS maps. Parcel-scale findings are illustrated in Figure 2

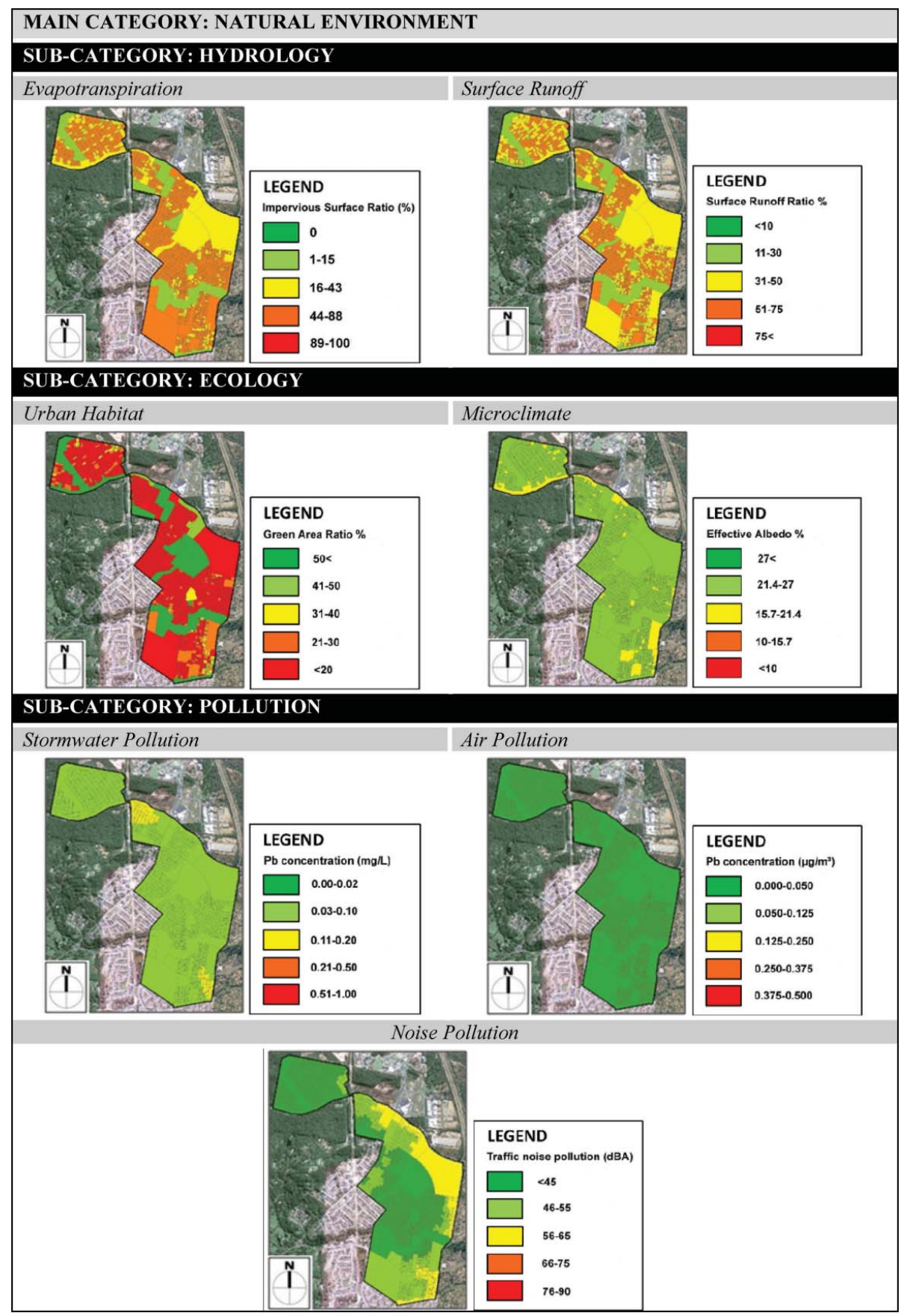

Figure 2. Parcel-level findings of the indicators. 

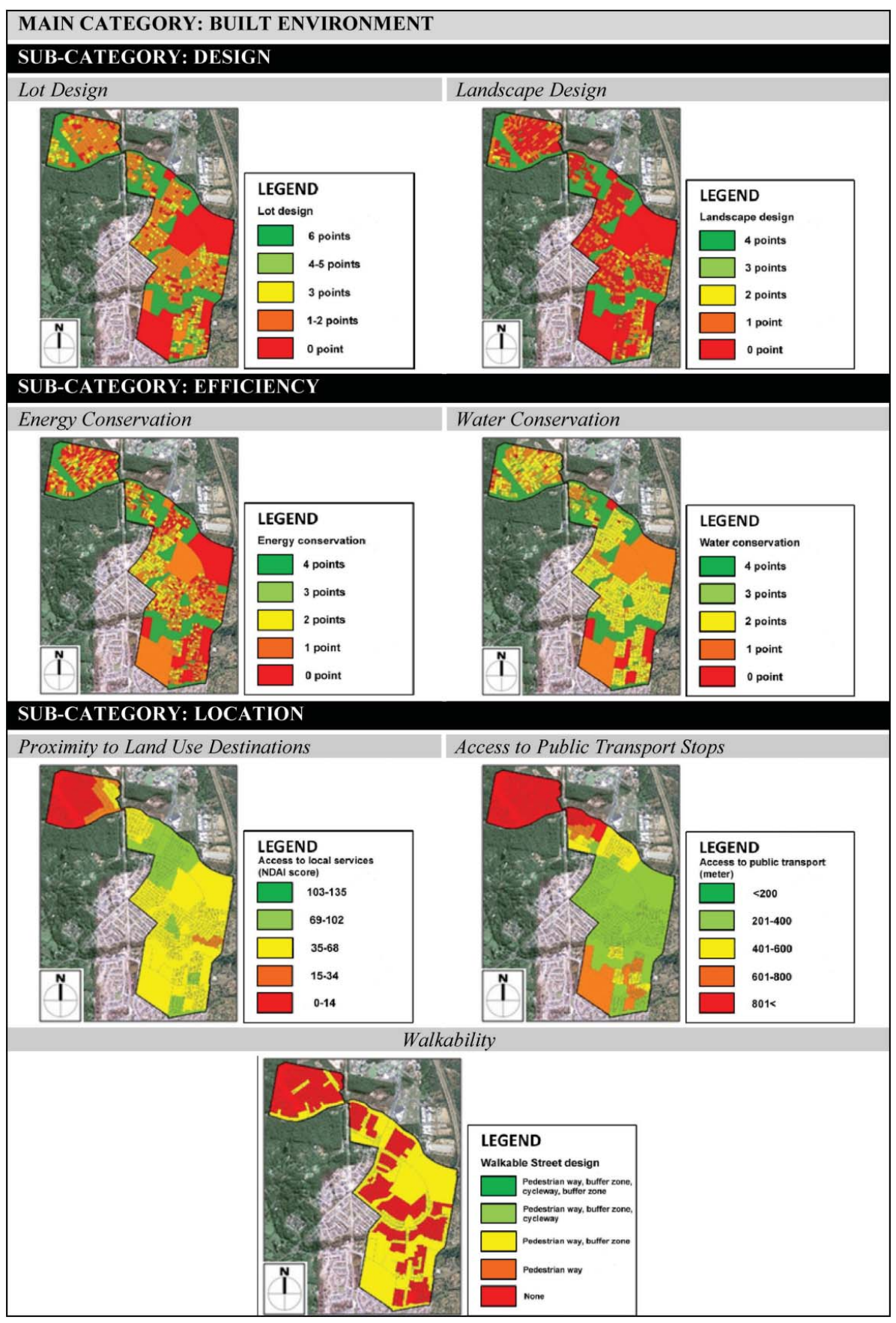

Figure 2. (Continued). 


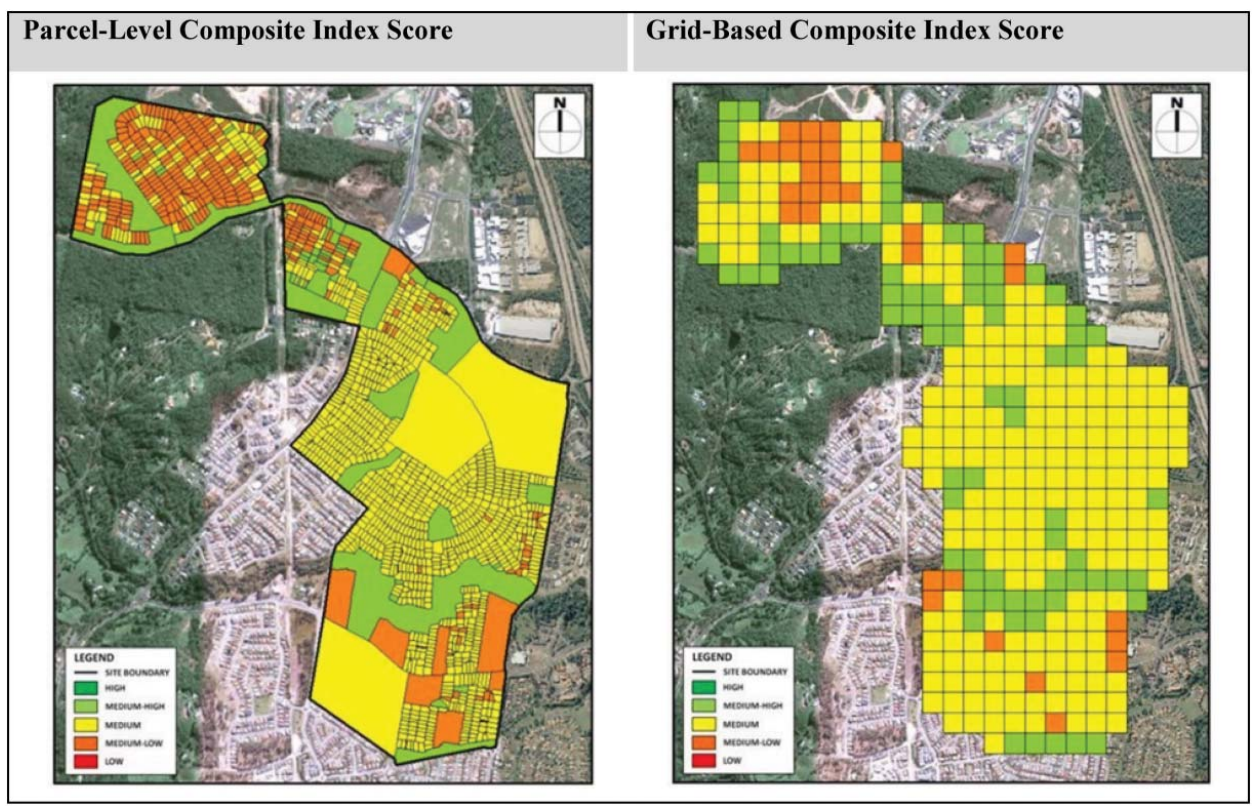

Figure 3. Grid-based composite index scores.

In addition to parcel-scale information, the outcomes of this study are also presented at the grid cell scale to easily integrate parcel-scale model outputs with the different scale assessment tools in the local planning process. Composite index maps of the site are illustrated in Figure 3.

The grid-based composite index score of the area is medium (2.01-3.00). The composite index score shows that the growing residential pressure in the area results in increased impervious surfaces (composite score: 2.16/sustainability performance: medium), which have significant impacts on the site hydrology through excessive SR rates (composite score: 2.34/sustainability performance: medium). In addition, the cardependent pattern of development in the area contributes to SR by creating more impervious surfaces thereby increases the risk of transporting pollutants into water resources (composite score: 3.90/sustainability performance: medium-high). An increase in the impervious surfaces also affects the ecology of the area by clearing natural vegetation (composite score: 1.23/sustainability performance: medium-low). The development patterns in the area create an environment that discourages pedestrian and bicycle travel (composite score: 1.46/sustainability performance: medium-low). As the area is highly dependent on motor vehicle use, there is limited accessibility by walking $800 \mathrm{~m}$ - to land-use destinations (composite score: 2.84/sustainability performance: medium). Lastly, the results indicate that climate responsive design strategies in terms of energy and water efficiency aspects are not common in the area (composite score: $2.57 /$ sustainability performance: medium).

Evaluation is a key component of the policy-making process. It is a means of determining the appropriateness, effectiveness, and efficiency of government policies and programs, and contributing to policy improvements and innovation (ACT 2010, 3). Evaluation of existing policies provides an understanding of what works, what is being done well, what should be followed or vice versa. By defining their strengths and 
weaknesses, governments and policy makers can enhance the quality of services they provide. In light of the model findings, evaluation of existing policies can be categorized under the following headings.

\subsection{Sustainable stormwater management}

The sustainability performance score of 'Site Hydrology' category is medium (composite score is 2.25). Specifically, the large percentage of impervious surfaces (51\%) due to high-density development lowers the rate of evapotranspiration $(33 \%)$ in the area. Moreover, as a result of auto-dependent development, the area is largely covered by paved surfaces (e.g., asphalt, concrete) with increased rates of SR (52\%). The results show that the type of development has adverse impacts on waterways, with stormwater pollution posing a major threat to waterway health. To guide stormwater management activities, the City Council prepared a Stormwater Quality Management Plan (GCCC 2015d) which is applicable to all types of land development and re-development. In this plan, the City Council adopted WSUD practices under the city's planning scheme to provide an integrated approach for SR management. Nevertheless, the results indicate that the implementation of these policies is not so successful in the area. Not all of the communities in the area are spending and investing in those strategies which have a range of social, environmental, and economic benefits. It is clear that the City Council should encourage individual landowners and community groups to install sustainable stormwater systems through a variety of regulations, educational, or incentive programs.

\subsection{Sustainable ecosystem management}

The sustainability performance score of 'Site Ecology' category is medium (composite score is 2.63). As most of the parcels have large amounts of impervious surfaces, the results demonstrate a very low green area ratio (11\%) in the area. There are only a few large urban green spaces in the site; which unfortunately, are threatened by development pressure. The microclimate and thermal effect of the site is generally favourable (effective albedo is 24\%) as parcels mostly have light-coloured roofs and surfaces related to the climatic conditions. The results show that the area is losing its native vegetation cover from increased impervious surfaces and canal construction. In response, the City Council proposed a Nature Conservation Assistance Program (GCCC 2015f) which provides financial assistance to individual landowners for on-ground restoration projects to protect wildlife habitat on private property. Furthermore, the rehabilitation of endangered and threatened species is protected through the Nature Conservation Strategy (GCCC 2015c). However, the results reveal that the community awareness of environmental issues in the area, as well as the policies to encourage the conservation of biodiversity, need to be enhanced. Additionally, the new developments should be built on previously developed, degraded, or brownfield sites that have no ecological value.

\subsection{Environmental quality}

The sustainability performance score of 'Site Pollution' category is medium-high (composite score is 4). The pilot site is located in the periphery of the city adjacent to the woodlands, hence the results represent a good picture of stormwater quality $(0.09 \mathrm{mg} / \mathrm{L})$, air quality $\left(0.014 \mu \mathrm{g} / \mathrm{m}^{3}\right)$, and noise pollution level (36dBA). To promote environmental quality, the Queensland Government established two pollution prevention policies: 
Environmental Protection (Water) Policy 2009 and Environmental Protection (Air) Policy 2008. Furthermore, Environmental Health and City Law Services provided an online lodgement system for reporting noise complaints. However, it has to be mentioned that the rest of the study area is mostly made up of human-made canals and waterfront dwellings that affect water quality. In this context, the natural hydrology of the water systems needs to be protected by reducing the construction of man-made water bodies. The results also show that there is growing stormwater pollution due to the high level of car dependency. Therefore, transport-related air pollution and emissions need to be reduced by promoting green transportation.

\subsection{Climate responsive urban design}

The sustainability performance score for the 'Site Design' category is medium-low (1.97). Climate responsive site design plays an important role in encouraging energy efficiency in subtropical regions like the study area (Kennedy 2010). The City Council prepared Energy Conservation (Design for Climate) (GCCC 2015e) policy under the city's planning scheme to reduce greenhouse gas emissions arising from energy consumption, in accordance with the Kyoto Protocol and the Cities for Climate Protection program. The policy consists of passive solar design principles such as lot shape, building orientation, solar access, and so on. Unfortunately, most of the parcel layouts do not meet these principles. Due to high-density development, most of the parcels do not have gardens or green spaces; hence, the site presents very poor performance regarding subtropical landscape design (composite score: 1.60/sustainability performance: medium-low). The results show that the study area lacks green spaces. Therefore, eco-friendly landscape design needs to be integrated into the built environment in order to support local biodiversity by using endemic vegetation.

\subsection{The use of renewable resources}

The sustainability performance score for the 'Site Efficiency' category is medium (2.57). The results show that existing parcel layouts do not meet the principles of energy and water efficient designs, such as encouraging alternative sources, using sustainable roof and paving materials as well as water-saving systems. Most of the parcels do not use sustainable energy sources, such as solar panels. In response, the Australian Greenhouse Office, a Federal Government initiative, offers rebates for installing photovoltaic (PV) cells. The water conservation of the area is generally favourable, as the results indicate a high rate of rainwater tank usage (composite score: 3.00/sustainability performance: medium). Sustainable water initiatives taken by the government has certainly impacted on the behaviour of residents. For instance, the City Council offers free sustainable gardening workshops to promote water efficient gardening through composting, worm farming, plant grouping, and mulching. Moreover, the City Council established a watersaving tips brochure which is designed to make water conservation in homes and gardens.

\subsection{Sustainable mobility and accessibility}

The sustainability performance score for the 'Site Location' category is medium (2.43). The results indicate that the area has limited accessibility to land-use destinations by walking (Neighbourhood Destination Accessibility Index score: 51). Specifically, the northern part of the site has very limited accessibility to LUD by walking (street design is 
solely composed of pedestrian way, no cycleway, and buffer zone) as well as access to PT stops (628 meter). As a result of automobile oriented land-use patterns in the area, automobile dependency needs to be reduced by providing different transport modes and mixed-use neighbourhood centres. Moreover, PT needs to be encouraged in the area by providing efficient PT routes and times. In response, the Gold Coast City Transport Strategy 2031 (GCCC 2015g) aims to reduce car dependency by creating an integrated and sustainable transport system. Some of the initiatives in this plan involve: Gold Coast light rail, Council cab services assisting older people and those with disability, oncology patient transport, and car sharing.

\section{Conclusion}

By developing and testing MUSIX, this research validates that parcel-based spatial analysis can be used as an assessment tool for the local planning scheme to evaluate the sufficiency of existing policies. The model findings provide many advantages in guiding development of policies at local level. First, the model serves as a rating tool for evaluating the existing development by highlighting environmental opportunities and constraints in the area. Second, it serves as a design tool for assisting the environmental quality of future urban areas by setting standards for energy-efficient and climateresponsive residential parcel design. Third, it assists governments and planning institutions to monitor urban ecosystems by providing quantitative information on the impacts of development on the environment (Dizdaroglu and Yigitcanlar 2014). MUSIX also assists different stakeholders by (1) helping master planned communities and developers to rate the sustainability of their development which can also be linked to other sustainability rating systems - such as BREEAM, LEED, Green Star, and CASBEE; (2) assisting local governments to detect environmentally problematic areas in the existing settlements, thereby; this information can be used to improve the future development of infrastructure and services, and; (3) increasing the awareness of individual residents on the environmental issues and the model findings can be used by them to make sustainable improvements in their residential parcels.

On the other hand, MUSIX has limitations. The main limitation of this research was the lack of reliable data during the indicator selection. At the beginning of the study, a comprehensive list of indicators was developed. However, the indicators which are related to socio-economic structure (e.g., household density, income, education, family size, immigration status) were excluded due to problems with individual or household level data collection and privacy issues. As a further research direction, a postdoc research will be carried out to examine the impacts of socio-economic structure of the urban ecosystem on sustainability. The indicators were selected by considering data availability of the Gold Coast area. The same indicator list can be adapted and applied by other local authorities within the greater region. To implement this methodology in different local areas, the indicator-base of the model needs to be customized in relation to the land use and environmental characteristics and parcel-scale data coverage. Furthermore, some challenges occurred during land cover detection through aerial remote sensing data. Because of poor data resolution, weather conditions or shadowing issues, the images were not detectable for some residential areas, hence; some practical and time-efficient solutions were implemented for the success of the study. Lastly, the size of the parcels in the area range from 500 to $2,000 \mathrm{~m}^{2}$. For any parcels larger than this size, such as schools or retail centres, it needs to be taken into consideration that the parcel- 
scale might cause loss of detail. In such cases, an alternative approach should be considered.

As an extension of this research, by integrating with the social and economic aspects of sustainability, the model can be further developed to measure the sustainability performance of other local contexts. For instance, at the local level, household surveys provide valuable insights into how the existing environmental policies respond to their own needs and use of resources. Additionally, possible directions for the future design and application of MUSIX could be combined with a new module for evaluating development scenario alternatives. By producing accessible, easily combined parcelbased data, the model findings can support planners and managers in the decision-making process, including the following benefits: (1) providing information to compare during the evaluation of proposed development projects or plans; (2) helping practitioners to choose the most appropriate plan to accomplish sustainability goals; (3) providing collaboration between different government bodies that are needed to ensure the creation of sustainable urban ecosystems.

\section{Acknowledgements}

The authors wish to acknowledge the contribution of the project partners, research team and expert panel members.

\section{Disclosure statement}

No potential conflict of interest was reported by the authors.

\section{Funding}

This paper is an outcome of an Australian Research Council Linkage Project [grant number ARCLP0882637], jointly funded by the Commonwealth Government of Australia, Gold Coast City Council, Queensland Transport and Main Roads, and Queensland University of Technology (QUT).

\section{ORCID}

Tan Yigitcanlar (1) http://orcid.org/0000-0001-7262-7118

\section{References}

ABS (Australian Bureau of Statistics). 2015. Gold Coast City Community Profile. Accessed June 10, 2015. http://profile.id.com.au/gold-coast

ACT. 2010. Australian Capital Territory Government Evaluation Policy and Guidelines, Canberra: ACT Government. Accessed June 10, 2015. http://www.cmd.act.gov.au/_data/assets/pdf_file/ 0004/175432/ACT-Evaluation-Policy-Guidelines.pdf

Alberti, M. 2008. Advances in Urban Ecology: Integrating Humans and Ecological Processes in Urban Ecosystems. Seattle, WA: Springer Science Business Media, LLC.

Can, A., M. Rademaker, T. Van Renterghem, V. Mishra, M. Van Poppel, A. Touhafi, J. Theunis, B. De Baets, and D. Botteldooren. 2011. "Correlation Analysis of Noise and Ultrafine Particle Counts in a Street Canyon." Science of the Total Environment 409: 564-572.

Carraro, C.F., C. Ciampalini, S. Cruciani, and E.L. Giove. 2009. The FEEM Sustainability Index (FEEM SI) Methodological Report. Accessed April 15, 2012. www.feemsi.org

Christmann, E.P., and J.L. Badgett. 2009. Interpreting Assessment Data: Statistical Techniques You Can Use. Washington, DC: NSTA Press.

Dizdaroglu, D. 2015. "Developing Micro-Level Urban Ecosystem Indicators for Sustainability Assessment." Environmental Impact Assessment Review 54: 119-124. 
Dizdaroglu, D., and T. Yigitcanlar. 2014. "A Parcel-Scale Assessment Tool to Measure Sustainability Through Urban Ecosystem Components: The MUSIX Model." Ecological Indicators 41: 115-130.

Dramstad, W., M. Tveit, W. Fjellstad, and G. Fry. 2006. "Relationships between Visual Landscape Preferences and Map-Based Indicators of Landscape Structure." Landscape and Urban Planning 78: 465-474.

Dur, F., T. Yigitcanlar, and J.M. Bunker. 2014. "A Spatial-Indexing Model for Measuring Neighbourhood-Level Land-Use and Transport Integration." Environment and Planning $B$ 41 (5): $792-812$.

EEA. 2005. EEA Core Set of Indicators Guide, Technical report: No. 1/2005. Copenhagen: EEA.

GCCC. 2006. Gold Coast Our Living City Report 2005-06. Gold Coast City: GCCC.

GCCC. 2008. Our Land Use Future - Best Practice Research Report. Gold Coast City: GCCC. http://www.boldfuture.com.au/pdf/OUR_LAND_USE_FUTURE_BEST_PRACTICE_RE SEARCH_REPORT.PDF

GCCC. 2012. Gold Coast City Council Annual Report 2010-11. Gold Coast City: GCCC. http:// www.goldcoast.qld.gov.au/documents/bf/annual-report-2010-11-full.pdf

GCCC. 2015a. City of Gold Coast's Corporate Plan 2020. Gold Coast City: GCCC. http://www. goldcoast.qld.gov.au/documents/bf/cogc-corporate-plan-gc-2020.pdf

GCCC. 2015b. Draft City Plan 2015. Accessed June 16, 2015. http://www.goldcoast.qld.gov.au/ planning-and-building/city-plan-2015-19859.html

GCCC. 2015c. Nature Conservation Strategy (2009-2019). Gold Coast City: GCCC. http://www. goldcoast.qld.gov.au/nature-conservation-strategy-2009-19-report-4559.html

GCCC. 2015d. Stormwater Quality Management Plan. Gold Coast City: GCCC. http://www.gold coast.qld.gov.au/gcplanningscheme_0509/attachments/policies/policy11/section_13_1_storm water_quality_management_guidelines.pdf

GCCC. 2015e. Energy Conservation (Design for Climate). Gold Coast City: GCCC. http://www. goldcoast.qld.gov.au/gcplanningscheme_0305/support_files/scheme/12_policy_05.pdf

GCCC. 2015f. Nature Conservation Assistance Program - Guidelines. Accessed June 16, 2015. http://www.goldcoast.qld.gov.au/nature-conservation-assistance-program-guidelines-14163. html

GCCC. 2015g. Gold Coast City Transport Strategy 2031. Gold Coast City: GCCC. http://www.gold coast.qld.gov.au/documents/bf/GC-transport-strategy-2031.pdf

Google Maps. 2013. Discovery Drive, Helensvale, QLD, Australia [Site Map]. Accessed October 11, 2013. https://maps.google.com/maps?q=gold+coast+abraham+road\&ie=UTF$8 \& \mathrm{hq}=\&$ hnear $=0 \times 6 \mathrm{~b} 9113 \mathrm{fc} 8095448 \mathrm{~b}: 0 \mathrm{xf5} 1 \mathrm{fb} 6 \mathrm{f} 90573 \mathrm{e} 3 \mathrm{e} 2$,Abraham $+\mathrm{Rd},+$ Upper + Coomera + QLD+4209,+Australia\&gl=tr\&ei=IRnsUoyeF8nriAeH9ID4CQ\&ved=0CCMQ8gEwAA

Groh, A.P., and M. Wich. 2009. A Composite Measure to Determine a Host Country's Attractiveness for Foreign Direct Investment, RP D/833, Barcelona: IESE Business School, University of Navarra.

Groh, A.P., H. von Liechtenstein, and K. Lieser. 2008. The European Venture Capital and Private Equity Country Attractiveness Index(es), RP D/773, Barcelona: IESE Business School, University of Navarra.

Guidotti, T.L. 2010. "Health and Urban Ecosystems." Archives of Environmental and Occupational Health 65 (1): 54-55.

Guijt, I., and A. Moiseev. 2001. Resource Kit for Sustainability Assessment. Gland: IUCN.

Hardi, P., S. Barg, T. Hodge, and S. Pinter. 1997. Measuring Sustainable Development: Review of Current Practice, Occasional Paper Number 17. Ottawa, Canada: Industry Canada.

Japan Sustainable Building Consortium. 2007. CASBEE (Comprehensive Assessment System for Building Environmental Efficiency) for Home and Urban Development Technical Manual. Accessed August 17, 2010. http://www.ibec.or.jp/CASBEE/english/

Katz, M.H. 1999. Multivariable Analysis: A Practical Guide for Clinicians. Cambridge: Cambridge University Press.

Kennedy, R. 2010. Subtropical Design in South East Queensland: a Handbook for Planners, Developers and Decision-Makers. Brisbane: The Centre for Subtropical Design, QUT Queensland University of Technology, Accessed April 22, 2015. www.subtropicaldesign.org.au

Lehman, A., N. O'Rourke, L. Hatcher, and E. Stepanski. 2005. JMP for Basic Univariate and Multivariate Statistics: A Step-By-Step Guide. Cary, NC: SAS Institute, Inc.

Morien, D. 2006. Business Statistics. Melbourne: Thomson. 
Ness, B., E. Urbel-Piirsalu, S. Anderberg, and L. Olsson. 2007. "Categorising Tools for Assessing Sustainability." Ecological Economics 60 (3): 498-508.

Newman, P., and I. Jennings. 2008. Cities as Sustainable Ecosystems: Principles and Practices. Washington, DC: Island Press.

OECD. 2003. Environmental Indicators: Development, Measurement and Use, Reference Paper. Paris: OECD.

Paez, A., and D.M. Scott. 2004. "Spatial Statistics for Urban Analysis: A Review of Techniques with Examples." GeoJournal 61 (1): 53-67.

Pinho, O.S., and M.D. Manso Orgaz. 2000. "The Urban Head Island in a Small City in Coastal Portugal." International Journal of Biometeorology 44: 198-203.

Raju, K., D. Lucien, and C. Arondel. 2000. "Multi Criterion Analysis for Sustainable Water Resources Planning." Water Resources Management 14: 435-456.

Rinner, C., and M. Hussain. 2011. "Toronto's Urban Heat Island-Exploring the Relationship between Land Use and Surface Temperature." Remote Sensing 3: 1251-1265.

Saisana, M. 2010. ELLI-Index: A Sound Measure for Lifelong Learning in the EU, EUR 24529 EN. JRC-IPSC. Italy: Guropean Commission.

Saltelli, A., M. Nardo, M. Saisana and S. Tarantola: 2004, "Composite Indicators - the Controversy and the Way Forward" paper presented at the OECD World Forum on Key Indicators, Palermo, November 10-13. http://www.oecd.org/dataoecd/40/50/33841312.doc

Schulman, A., and C.A. Peters. 2008. "GIS Analysis of Urban Schoolyard Landcover in Three U.S. cities." Urban Ecosystems 11 (1): 65-80.

SEDAC. 2007. Compendium of Environmental Sustainability Indicators. New York, USA: The Socioeconomic Data and Applications Center (SEDAC), Center for International Earth Science Information Network (CIESIN), Columbia University. Accessed June 6, 2009. http://sedac.cie sin.columbia.edu/es/compendium.html

Singh, R.K., H.R. Murty, S.K. Gupta, and A.K. Dikshit. 2009. "An Overview of Sustainability Assessment Methodologies." Ecological Indicators 9 (1): 189-212.

Srinivasan, R.S., W.W. Braham, D.E. Campbell, and D.C. Curcija. 2011. "Sustainability Assessment Frameworks, Evaluation Tools and Metrics for Building and Environment - A Review." In Proceedings of the Twelfth International Building Performance Simulation Association Conference, Sydney, Australia, 2011. 350-357. Paper presented at the 12th Conference of the International Building Performance Simulation Association, Sydney, November 14-16. http://www.ibpsa.org/proceedings/BS2011/P_1218.pdf

U.S. Green Building Council. 2008. LEED (Leadership in Environmental and Energy Design) for Homes Rating System. Accessed October 6, 2009. Washington, DC: USGBC. http://www. usgbc.org/

U.S. Green Building Council. 2009. LEED (Leadership in Environmental and Energy Design) for Neighbourhood Development. Accessed October 6, 2009. Washington, DC: USGBC. http:// www.usgbc.org/

UNCSD. 2001. Indicators of Sustainable Development: Guidelines and Methodologies. New York: United Nations.

UNEP. 2003. UNEP Initiative on Capacity Building for Integrated Assessment and Planning for Sustainable Development, unpublished, Geneva, April 2003.

Yigitcanlar, T., ed. 2010. Rethinking Sustainable Development: Urban Management, Engineering and Design. Hersey, PA: IGI Global.

Yigitcanlar, T., N.G. Sipe, R. Evans, and M. Pitot. 2007. "A GIS-Based Land Use and Public Transport Accessibility Model.” Australian Planner 44 (3): 30-37. 


\section{References for Appendix 1}

Akbari, N., S. Davis, S. Dorsano, J. Huang, and S. Winnett, eds. 1992. Cooling Our Communities: A Guidebook on Tree Planting and Light-Colored Surfacing. Washington, DC: USEPA.

ASCE/WEF (Water Environment Federation and American Society of Civil Engineers). 1992. Design and Construction of Urban Storm Water Management Systems, ASCE Manuals and Reports of Engineering Practice No. 77, WEF Manual of Practice FD-20. Reston, VA: WEF and ASCE.

Caltrans (California Department of Transportation). 2001. "Hydrology" Chapter 810 in, Highway Design Manual Sacramento, CA: Caltrans. Accessed April 15, 2012. http://www.dot.ca.gov/hq/ oppd/hdm/pdf/chp0810.pdf

CASBEE. 2007. Comprehensive Assessment System for Building Environmental Efficiency for Urban Development-Technical Manual, Japan Sustainable Building Consortium (JSBC)/ Japan GreenBuild Council (JaGBC). Accessed October 15, 2011. http://www.ibec.or.jp/CAS BEE/english/index.htm

City of Springfield. 2007. Springfield Storm Drainage Criteria Manual. Accessed April 15, 2012. http://www.springfieldmo.gov/stormwater/pdfs/Criteria/Chapter5.pdf

DEWHA (Department of the Environment, Water, Heritage and the Arts). 2008. Your Home Technical Manual. 4th ed. Accessed April 15, 2012. http://www.yourhome.gov.au/technical/ fs $41 . h t m l$

DOT/Welsh Office. 1988. Calculation of Road Traffic Noise. London: HMSO.

DSEWPC. 2001. State of Knowledge Report: Air Toxics and Indoor Air Quality in Australia. Canberra: ACT: Department of Sustainability, Environment, Water, Population and Communities.

Dur, F. 2012. The Integrated Land Use and Transportation Indexing Model: Assessing the Sustainability of Gold Coast, Australia. PhD by Publication, Queensland University of Technology.

German Solar Energy Society. 2008. Planning and Installing Photovoltaic Systems: a Guide for Installers, Architects and Engineers. Abingdon: Routledge.

Hyde, R. 2000. Climate Responsive Design -A Study of Buildings in Moderate and Hot Humid Climates. Oxon: E and FN Spon.

King, S., D. Rudder, D. Prasad, and J. Ballinger. 1996. Site Planning in Australia: Strategies for Energy Efficient Residential Planning. Canberra: AGPS.

Kloth, M., K. Vancluysen, and F. Clement. 2008. Practitioner Handbook for Local Noise Action Plans-Recommendations From the SILENCE Project. Austria: AVL List GmbH.

Lindeburg, M.R.. 1994. Civil Engineering Reference Manual, 9th ed. Belmont, CA: Professional Publications, Inc..

Mahbub, SrvBin. 2011. Impact of Urban Traffic and Climate Change on Water Quality from Road Runoff, $\mathrm{PhD}$ by Publication, Queensland University of Technology.

Markart G., B. Kohl, R. Kirnbauer, H. Pirkl, H. Bertle, R. Stern, A. Reiterer, P. Zanetti. 2006. "Surface Runoff in a Torrent Catchment Area in Middle Europe and Its Prevention." Geotechnical and Geological Engineering 24: 1403-1424.

Mavoa, S., K. Witten, J. Pearce, and P. Day. 2009. Measuring Neighbourhood Walkability in New Zealand Cities. Auckland: Centre for Social and Health Outcomes Research and Evaluation, Massey University.

NHMRC and NRMMC. 2004. Australian Drinking Water Guidelines 2004, National Water Quality Management Strategy, National Health and Medical Research Council and the Natural Resource Management Ministerial Council.

Nicklow, J.W., P.F. Boulos, and M.K. Muleta. 2006. Comprehensive Urban Hydrological Modelling Handbook for Engineers and Planners. Pasadena, CA: MWH Soft Publ.

ODOT. 2005. Hydraulics Manual. Oregon Department of Transportation Accessed April 15, 2012. $\mathrm{ftp} / / / \mathrm{ftp}$.odot.state.or.us/techserv/Geo-Environmental/Hydraulics/Hydraulics\%20Manual/Chap ter_07/Chapter_07_appendix_F/CHAPTER_07_appendix_F.pdf.

Oke, T.R. 1978. Boundary Layer Climates. London: Methuen.

Olgyay, V. 1963. Design with Climate, Bioclimatic Approach to Architectural Regionalism. Princeton, NJ: Princeton University Press.

Taha, H., H. Akbari, and A. Rosenfeld. 1988. "Residential Cooling Loads and the Urban Heat Island: The Effects of Albedo" Building and Environment 23: 271-283. 
US Environmental Protection Agency. 1993. Guidance Specifying Management Measures for Sources of Nonpoint Pollution in Coastal Waters, EPA 840-B-92-002, Washington, DC: Office of Water.

Watson, D., A.J. Plattus, and R.G. Shibley. 2003. Time-Saver Standards for Urban Design. New York: McGraw-Hill.

Witten, K., J. Pearce, and P. Day. 2011. "Neighbourhood Destination Accessibility Index: A GIS Tool for Measuring Infrastructure Support for Neighbourhood Physical Activity." Environment Plan A 43: 205-223. 


\section{Appendix 1. The normalization and calculation of indicators}

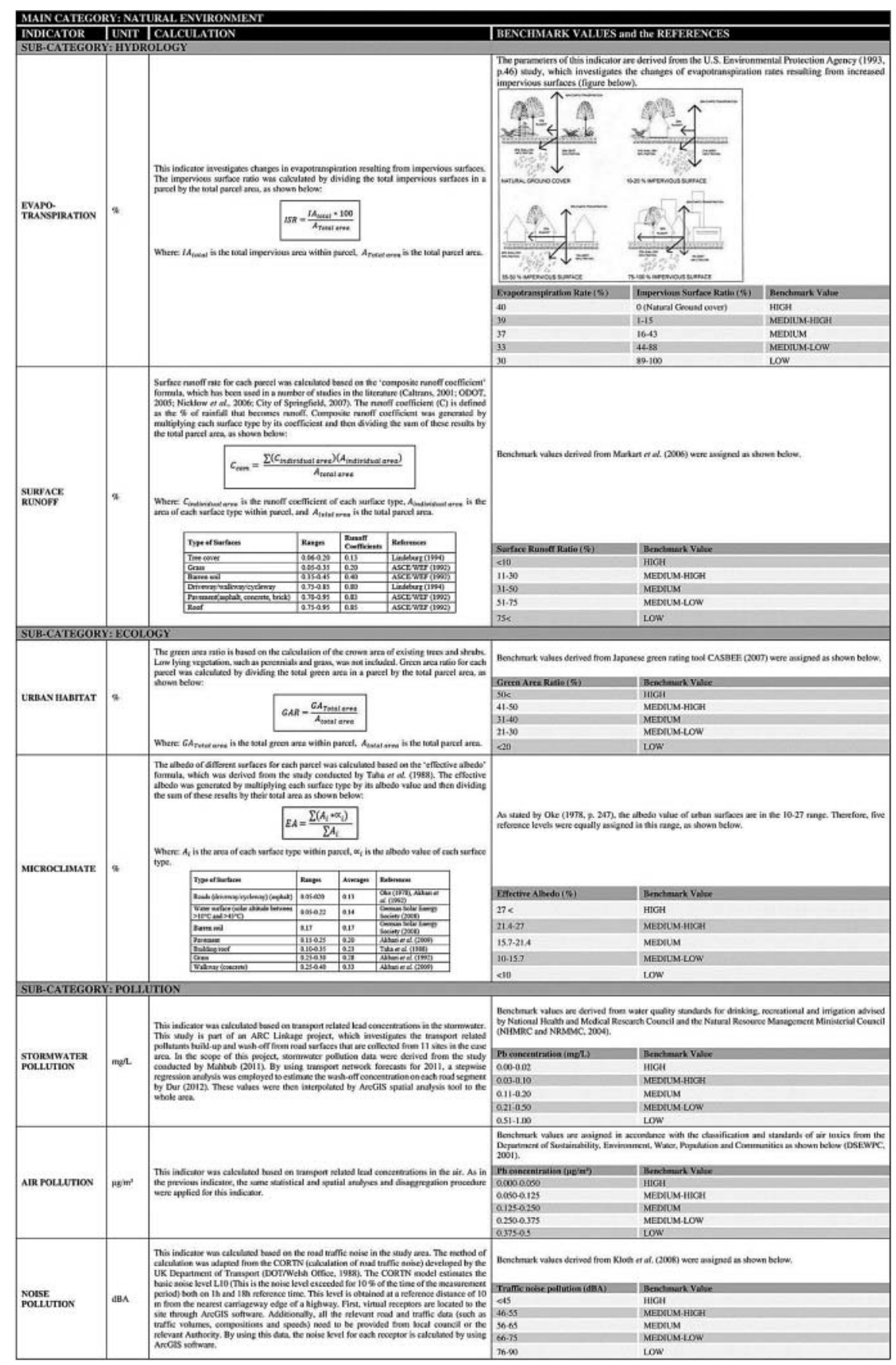


Appendix 1. (Continued)

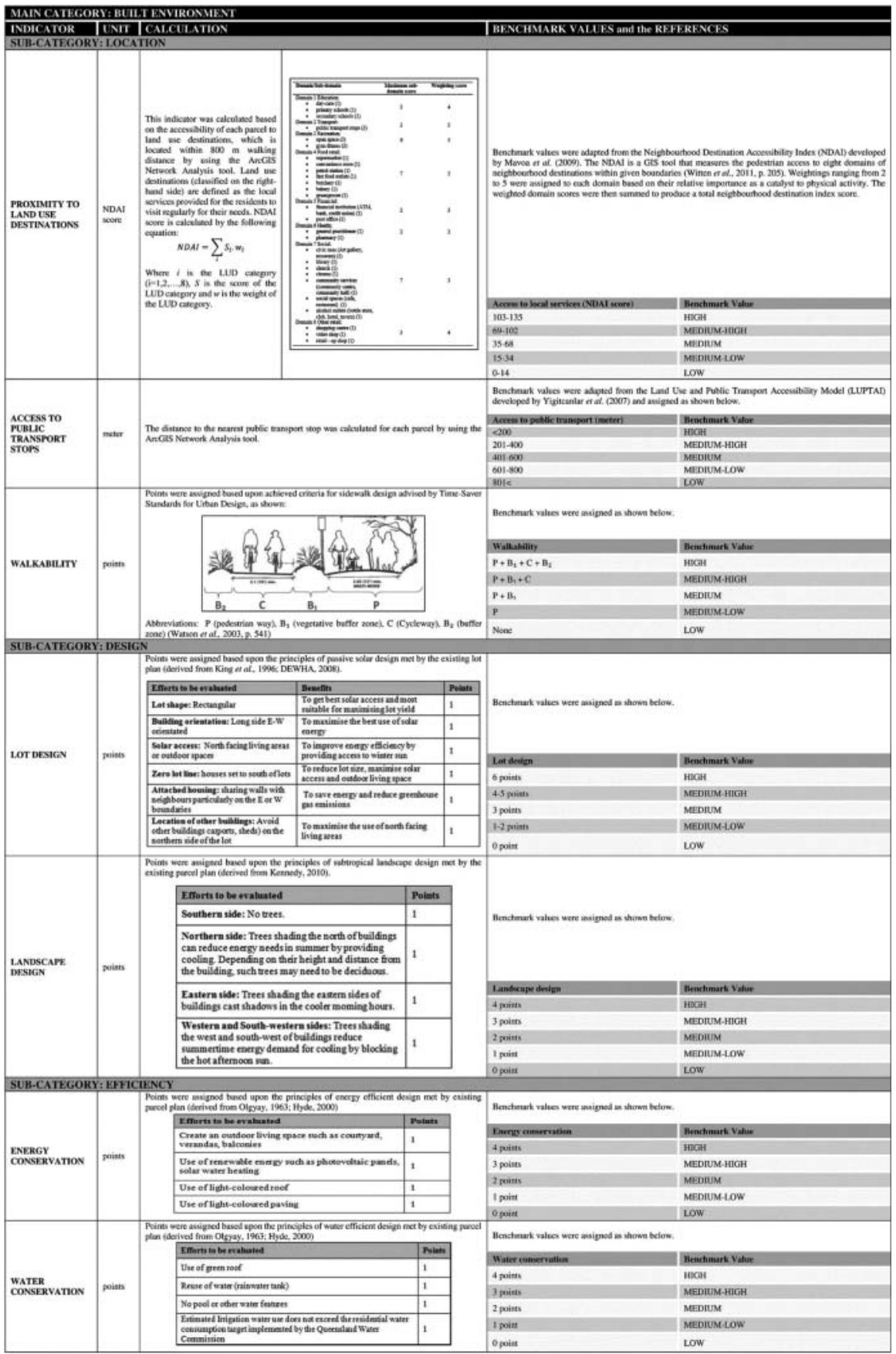


Appendix 2. Spearman correlation coefficients of the indicator set

\begin{tabular}{|c|c|c|c|c|c|c|c|c|c|c|c|c|c|c|}
\hline & ISR & SR & SW & AIR & NOISE & GAR & EA & LUD & PT & WLK & LOTDSG & LNDDSG & ENERGY & WATER \\
\hline ISR & 1.000 & & & & & & & & & & & & & \\
\hline SR & $0.734^{* *}$ & 1.000 & & & & & & & & & & & & \\
\hline SW & 0.005 & $0.062^{* *}$ & 1.000 & & & & & & & & & & & \\
\hline AIR & $0.075^{* *}$ & $0.120^{* *}$ & $0.648^{\text {*** }}$ & 1.000 & & & & & & & & & & \\
\hline NOISE & -0.034 & $-0.040^{* *}$ & $0.290^{* *}$ & $0.304^{* *}$ & 1.000 & & & & & & & & & \\
\hline GAR & $0.271^{* *}$ & $0.327^{* *}$ & 0.036 & 0.023 & $-0.132^{* *}$ & 1.000 & & & & & & & & \\
\hline EA & $0.070^{* *}$ & $0.044^{* *}$ & -0.018 & 0.013 & $0.066^{* *}$ & $-0.109^{* *}$ & 1.000 & & & & & & & \\
\hline LUD & $-0.099^{* *}$ & $-0.041^{* *}$ & $0.137^{* *}$ & $0.109^{* *}$ & $-0.169^{* *}$ & -0.012 & -0.035 & 1.000 & & & & & & \\
\hline PT & $-0.079^{* *}$ & 0.009 & $0.244^{* *}$ & $0.089^{* *}$ & $-0.105^{* *}$ & $0.064^{* *}$ & $-0.051^{* *}$ & $0.731^{* *}$ & 1.000 & & & & & \\
\hline WLK & $-0.075^{* *}$ & $-0.062^{* *}$ & $0.086^{* *}$ & 0.014 & $-0.059^{* *}$ & $0.058^{* *}$ & -0.021 & $0.177^{* *}$ & $0.188^{* *}$ & 1.000 & & & & \\
\hline LOTDSG & $0.301^{* *}$ & $0.256^{* *}$ & $-0.117^{* *}$ & $-0.053^{* *}$ & $-0.093^{* *}$ & 0.014 & $0.070^{* *}$ & $-0.114^{* *}$ & $-0.161^{* *}$ & 0.032 & 1.000 & & & \\
\hline LNDDSG & $0.460^{* *}$ & $0.445^{* *}$ & $-0.137^{* *}$ & -0.036 & $-0.190^{* *}$ & $0.427^{* *}$ & 0.000 & $-0.157^{* *}$ & $-0.113^{* *}$ & $\begin{array}{l}0.032 \\
-0.014\end{array}$ & $0.340^{* *}$ & 1.000 & & \\
\hline ENERGY & $0.282^{* *}$ & $0.250^{* *}$ & 0.022 & $0.110^{* *}$ & $0.060^{* *}$ & 0.016 & $0.068^{* *}$ & $-0.065^{* *}$ & $-0.053^{* *}$ & -0.011 & $0.306^{* *}$ & $0.271^{* *}$ & 1.000 & \\
\hline WATER & $0.241^{* *}$ & $0.234^{* *}$ & $0.212^{* *}$ & $0.216^{* *}$ & $0.127^{* *}$ & $-0.249^{* *}$ & $0.114^{* *}$ & $0.150^{* *}$ & $0.062^{* *}$ & 0.010 & $0.261^{* *}$ & $0.044^{* *}$ & $0.216^{* *}$ & 1.000 \\
\hline
\end{tabular}

**. Correlation is significant at the 0.05 level (2-tailed), $\mathrm{n}=2843$

Abbreviations: Impervious surface ratio (ISR), surface runoff (SR), stormwater pollution (SW), air pollution (AIR), noise pollution (NOISE), green area ratio (GAR), albedo (EA), land use destinations (LUD), public transport (PT), walkability (WLK), lot design (LOTDSG), landscape design (LNDDSG), energy consumption (ENERGY), and water consumption (WATER). High correlations are highlighted in bold. 
Appendix 3. Composite index maps calculated by alternative methodological techniques

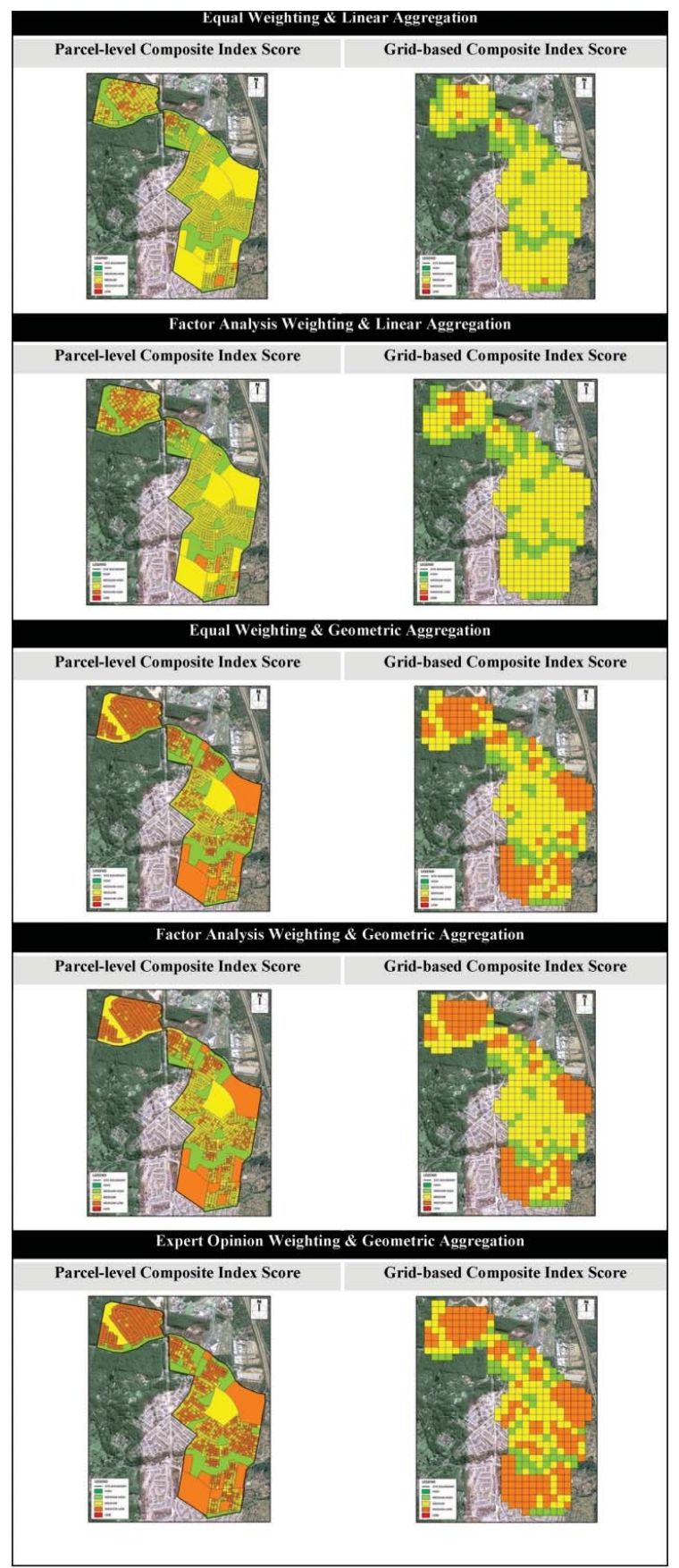

